\title{
Cooling control for castings by adopting skeletal sand mold design
}

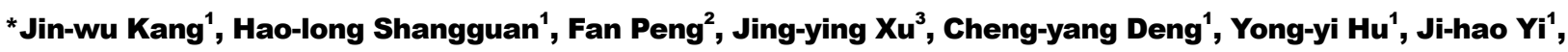 \\ Tao Huang ${ }^{4}$, Long-jiang Zhang ${ }^{2}$, Wei-min Mao ${ }^{3}$
}

1. School of Materials Science and Engineering, Key Laboratory for Advanced Materials Processing Technology, Tsinghua University, Beijing 100084, China

2. Kocel Machinery Limited, Ningxia 750021, China

3. School of Materials Science and Engineering, University of Science and Technology Beijing, Beijing 100083, China

4. Beijing DRUCK Technology Development Co. Ltd., Beijing 100084, China

\begin{abstract}
The cooling control of the melt during the casting process is of great significance. A comprehensive closed-loop cooling control of castings by adopting a skeletal sand mold design was proposed. The skeletal sand mold consisting of an adaptive shell, functional cavities and a support was designed and created based on the finite difference meshes of a casting. It was applied to a round wall test casting. Two kinds of skeletal sand molds, one with lattice support and the other with enforcing ribs for this casting were designed and printed out by the 3D printing (3DP) method. Aluminum alloy A356 was cast by using these two sand molds. The first mold was cooled by natural convection, the other one by water spray cooling. Two sound castings were obtained. The sand mold temperature, cooling curves, microstructures, mechanical properties, residual stress and deformation were measured, compared and discussed. Water spray cooling hastened the cooling rate by $62 \%$, increased the content of $\mathrm{Mg}$ and $\mathrm{Cu}$ in the $\mathrm{\alpha}-\mathrm{Al}$ matrix, improved the mechanical properties, and altered the surface residual stress state.
\end{abstract}

Key words: skeletal sand mold; 3D printing (3DP); casting; solidification; cooling
CLC numbers: TG146.21
Document code: A
Article ID: 1672-6421(2021)01-018-11

\section{Introduction}

Although many procedures are involved in casting production, the most important thing is the casting forming process in the molds. To control the cooling of castings in molds, the mold structure can be modified and molding materials can be properly selected. Chromite sand or zircon sand are usually used instead of silicon sand for the layer in contact with liquid metal for the making of large castings. Molds made of graphite and metals are also used in the casting industry, especially for dies which have long been used in the permanent mold casting and die casting, in which water cooling and oil heating channels are usually arranged ${ }^{[1,2]}$. In sand molds, pipes can be buried to circulate air or water or even liquid

\section{*Jin-wu Kang}

Ph.D, Associate Professor. His research interests mainly focus on the modeling and simulation of casting, solidification and additive manufacturing. He has published about 200 papers and received four academic awards from the Ministry of Education, China for his distinguished research.

E-mail: kangjw@tsinghua.edu.cn;

Received: 2020-11-23; Accepted: 2020-12-10 nitrogen to enforce the cooling of certain areas of a casting ${ }^{[3]}$. Similarly, in the making of plastic products, traditional cooling channels in metal molds are replaced by conformal cooling channels which are parallel to the cavity surface to improve the cooling efficiency. This kind of mold can be fabricated by additive manufacturing methods ${ }^{[4]}$. An ablation casting was invented to use water to erode away the sand mold step by step to realize the rapid solidification of a casting ${ }^{[5]}$. However, these methods face some drawbacks and have not yet extended to wide applications in sand casting. The $3 \mathrm{D}$ printing technologies have been gradually adopted in sand mold and core preparation. Among these technologies, the selective laser sintering (SLS) and $3 \mathrm{D}$ binder jetting printing (3DP) methods are becoming very attractive. These studies mainly focus on sand and binder materials, binder content, and mold properties, such as strength, permeability, gas release, and their influence on casting quality ${ }^{[6-13]}$. Combination of cores into a single one is also the benefit brought by $3 \mathrm{D}$ printing, with reduced stacking tolerances and improved dimensional accuracy ${ }^{[14,15]}$. The rigging system was redesigned based on the freedom of additive 
manufacturing sand mold. For example, a kind of conical-helix sprue was invented ${ }^{[16]}$. However, the basic structure of molds and cores is untouched because the fabrication cost by 3D printing is usually unacceptable. Cost is the main obstacle for the application of $3 \mathrm{D}$ printing in the casting industry.

Compared to the traditional manufacturing and forming methods, 3D printing makes possible the fabrication of more complicated structures. Many studies are managing to optimize the traditional part design by using shell, lattice, foam, or truss structures ${ }^{[17-19]}$. Shangguan et al. ${ }^{[20-23]}$ presented an additive manufacturing-driven mold design for castings: a hollow mold structure. This structure significantly improves the casting's cooling rate and greatly reduces the weight of the sand mold. It also provides the potential to further control the whole cooling process because of its feature of hollowness. Wang et al. ${ }^{[24]}$ proposed a multi-shell mold structure, and adopted it with waterimmersion cooling to enhance the heat insulation in the top and the cooling in the lower part so as to ensure the directional solidification of a casting.

In this study, a comprehensive closed-loop cooling control of castings by adopting the skeletal sand mold design was proposed. It was applied to a round wall test casting. Forced cooling was adopted to improve its cooling rate, microstructure and mechanical properties.

\section{Comprehensive closed-loop cooling control based on skeletal mold structure}

\subsection{Skeletal sand mold structure}

The freeform construction method in additive manufacturing provides freedom for the sand mold design. The skeletal sand mold structure is a hollow structure, including a shell, functional cavities and a lattice support, as shown in Fig. 1. The shell is for the containing of the liquid metal to form a casting. The functional cavities depend on the actual requirement of the adjustment of the cooling of the casting, such as cooling channels or insulation cavity. The lattice is to hold the hollow structure on the ground or for clamping during casting process. Therefore, this structure is self supporting, with no need of sand burying or holding by fixtures as in traditional shell molds. Cores are also hollow. As this kind of structure is additively manufactured, the mold and core are fabricated into a single piece, with no need of

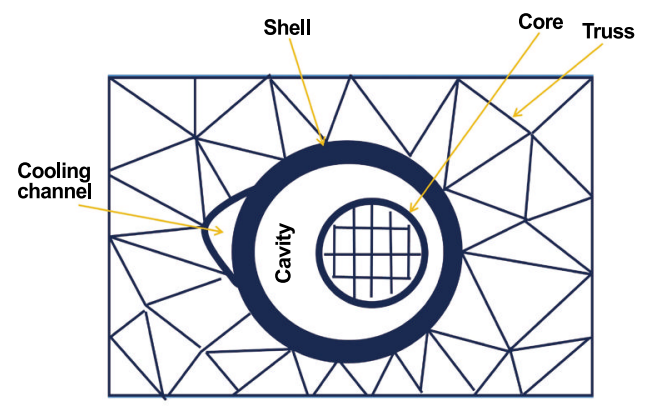

Fig. 1: Illustrative diagram of the skeletal sand mold consideration of their assembly.

\subsection{Design and creation of skeletal sand mold}

In CAD software, the shelling operation is widely used for additive manufacturing, but it can not create the functional cavities or the support structure. For complex structures like foam, lattice, and truss structure, although their basic elements seem simple, the boolean operations of these basic elements, such as union, difference, intersection, are usually intolerable, requiring a great amount of computer hard drive and memory space. Chen ${ }^{[25]}$ proposed a mesh-based geometric modeling method for cellular structures which used the boolean operations (especially intersections which need a substantial number of calculations) of the surface triangles from the STL file format. This is only useful for structures made of regular struts with round or square sections. Here, a unique method based on finite difference meshes is proposed for the design and creation of this kind of skeletal structure. The flowchart and illustration are shown in Figs. 2 and 3.

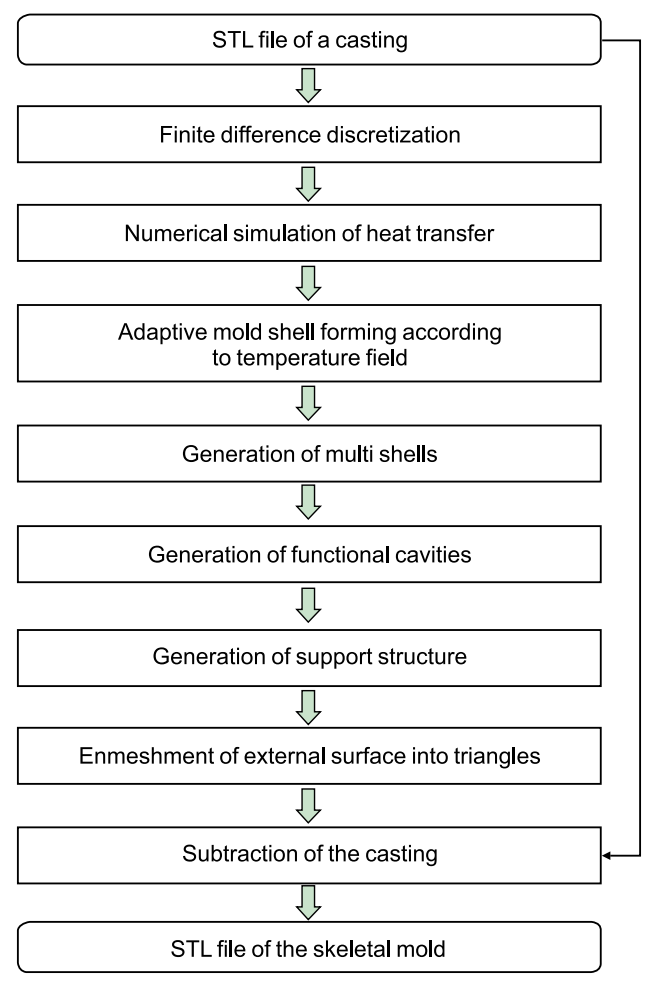

Fig. 2: Design flowchart for skeletal sand mold

Firstly, the STL file of a casting and its surrounding volume was meshed into regular cubes as the requirement for finite difference analysis. The surrounding volume serves as a solid mold for the foundation to make a hollow structure. To produce a thickness varying sand shell, numerical simulation of the heat transfer for the casting with atmosphere is performed based on the finite difference method. This heat transfer is governed by the Fourier equation:

$$
\rho c \frac{\partial T}{\partial t}=\frac{\partial}{\partial x}\left(k \frac{\partial T}{\partial x}\right)+\frac{\partial}{\partial y}\left(k \frac{\partial T}{\partial y}\right)+\frac{\partial}{\partial z}\left(k \frac{\partial T}{\partial z}\right)+\rho L \frac{\partial f_{\mathrm{s}}}{\partial t}
$$

where $\rho, c, k, L$ are the density, specific heat, thermal 


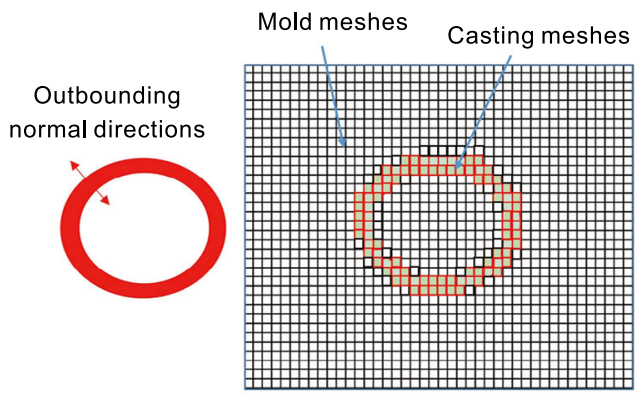

(a) (b)

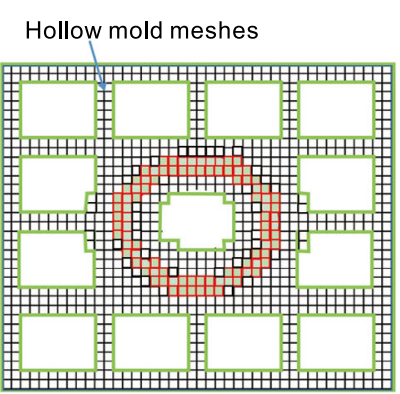

(c)

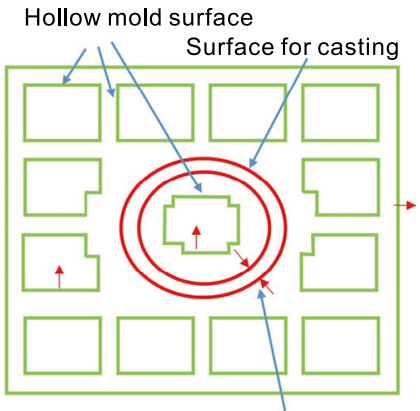

Inbounding normal directions

(d)

Fig. 3: 2D illustration of design of skeletal sand mold: (a) casting; (b) finite difference meshes; (c) creation of hollow mold; (d) generation of surfaces of hollow mold

conductivity, and latent heat of the casting, respectively, $T$ is temperature, $t$ is time, $f_{\mathrm{s}}$ is the solid fraction of the melt.

The initial temperature of the casting is supposed to be the pouring temperature, and the casting emits heat to the environment by convection and radiation. The boundary condition is:

$$
Q=h\left(T-T_{0}\right)
$$

where $h$ is the comprehensive heat transfer coefficient, including convection and radiation, $T_{0}$ is the environment temperature. The aim of the virtual heat transfer is to obtain the surface temperature distribution of the casting to determine the shell thickness instead of to acquire the accurate solidification time of the casting in the sand mold. Thus, the numerical simulation can be performed for a period of time, such as a half of the usual solidification time in sand mold, so as to exhibit an uneven surface temperature distribution. That means the calculation is very fast. This temperature distribution reflects the geometrical feature of the casting, thus, it is mapped to the shell thickness as follows:

$$
d_{(i, j, k)}=d_{\text {min }}+\frac{d_{\text {max }}-d_{\text {min }}}{T_{\text {max }}-T_{\text {min }}}\left(T-T_{\text {min }}\right)
$$

where $d_{(i, j, k)}$ is the shell thickness of $(i, j, k)$ mesh, $d_{\max }, d_{\min }$ are the maximum and minimum thickness of the sand shell, respectively, $T_{\max }, T_{\min }$ are the highest and lowest temperatures of the casting surface, respectively.

The meshes inside the above calculated thickness range are changed into hollow mold type. Multi layers of shells can be generated by altering the feature of the original mold meshes into air based on the given thickness of each layer of shell, their gaps, and the spacings. Multi layers of shells can be used for the risers to enhance heat insulation. Functional cavities such as air or water cooling channels can be generated by designating their diameter and location. Lattice structure is produced the same way based on the rod size, and spacings in $x, y, z$ directions. The surface meshes of the combination of the casting and hollow sand mold are identified, which avoids the inclusion of the interface between the casting and mold into surface meshes. Then, their exposed faces are meshed into triangles by splitting a rectangle into two triangles, as shown in Fig. 4. The casting cavity is created by subtracting the casting's surface of STL format. Then, the final design of the hollow mold is obtained. Both the external surface and the casting cavity surface are totally separated, thus, their subtraction is no intersection operation of triangles. Therefore, this creation method is very fast. Although this method is based on the regular finite difference meshes of a casting, the internal cavity for the casting is still kept as the original design, meaning the geometry of the casting isn't affected. This method is high efficient and automatic in replace of the manual and tedious operations in CAD software. The support structure can be a lattice or enforcing ribs on the shell surface. To avoid stress concentration at the abrupt section variations, the external surface of the hollow sand mold is smoothed. Two types of conjunctions are treated: one is the concave edges, the other is the concave corners, as shown in Fig. 5. These concave conjunctions of meshes can be filleted by modifying the coordinates of the corresponding vertices by Eqs. (4) and (5), respectively. The offset is less than the mesh size. The new coordinates are used in the surface discretization for the creation of the STL file.

$$
\begin{array}{r}
\left\{\begin{array}{l}
x^{\prime}=x+\Delta x \\
y^{\prime}=y+\Delta y
\end{array}\right. \\
\left\{\begin{array}{l}
x^{\prime}=x+\Delta x \\
y^{\prime}=y+\Delta y \\
z^{\prime}=z+\Delta z
\end{array}\right.
\end{array}
$$

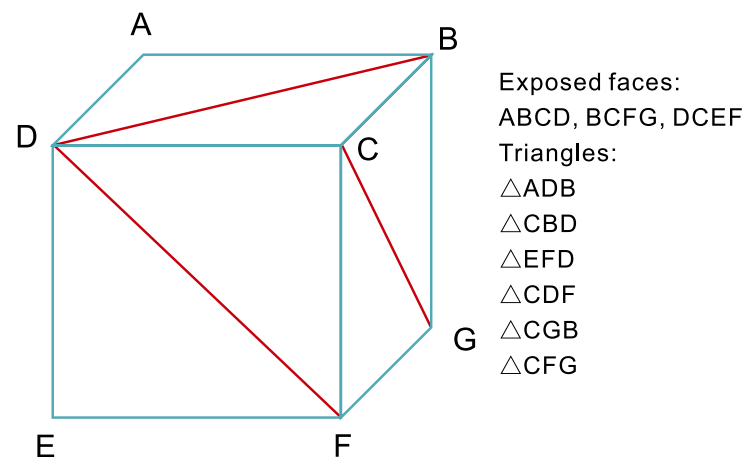

Fig. 4: Splitting of exposed surface into triangles for STL format 
(a)

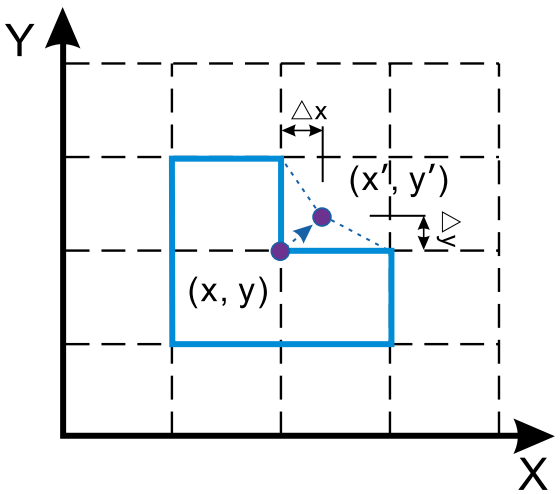

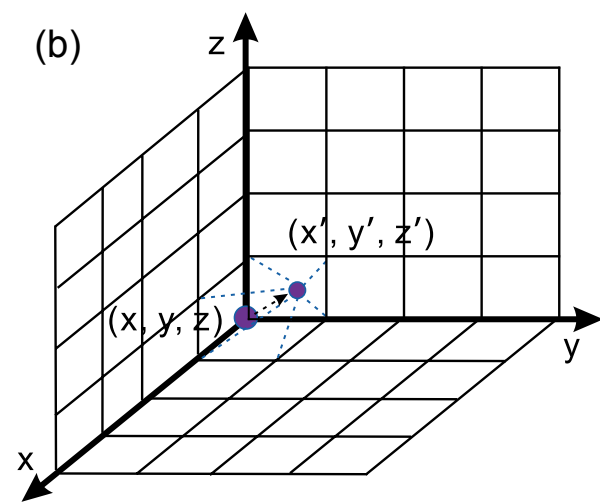

Fig. 5: Filleting of corners by offset location of corner vertices: (a) edge conjunction; (b) corner conjunction

\subsection{Comprehensive closed-loop cooling control}

This skeletal sand mold structure can be integrated into a comprehensive closed-loop cooling control system, as shown in Fig. 6. The shell provides a possibility to control the cooling of castings. A series of cooling nozzles or heaters can be arranged surrounding the shell, and temperature sensors can be embedded into the shell or attached to its surface. They can be connected to a control platform such as a programmable logic controller (PLC), with the nozzles serving as the actuator and the sensors serving as the input. The difference of the measured and set temperatures is used as the feedback to control the action of these cooling nozzles or heaters. Then, they can function at any required time and by any way, such as continuously or intermittently, according to requirements. For cooling, water, compressed air, liquid nitrogen, or other cooling media can be ejaculated from these nozzles to the shell surface. Thus, the comprehensive closed-loop cooling control of a casting can be realized. For example, the bottom of a casting can be chilled to facilitate its sequential solidification, the isolated hot spots can be fast cooled to avoid local shrinkage in replacement of chills, the risers and thick areas can be heated to prolong their solidification, and afterwards fast cooled to realize even cooling and then less residual stress.

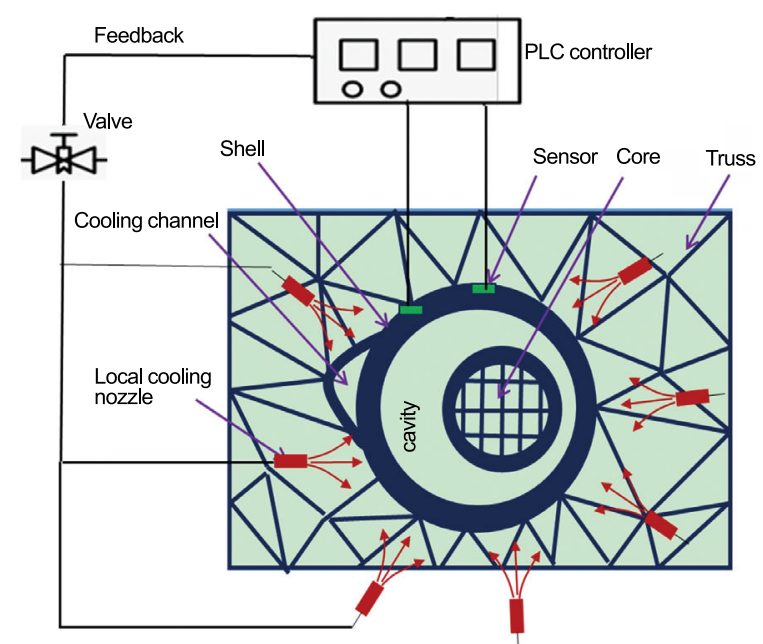

Fig. 6: Skeletal sand mold design and comprehensive closed-loop cooling control

\section{A case study - a round wall casting}

A round wall casting, a typical casting structure, as shown in Fig. 7, was selected for the application of this skeletal sand mold design. Its diameter is $300 \mathrm{~mm}$. The sprue is located at the center, and ten top waist shaped risers were designed.
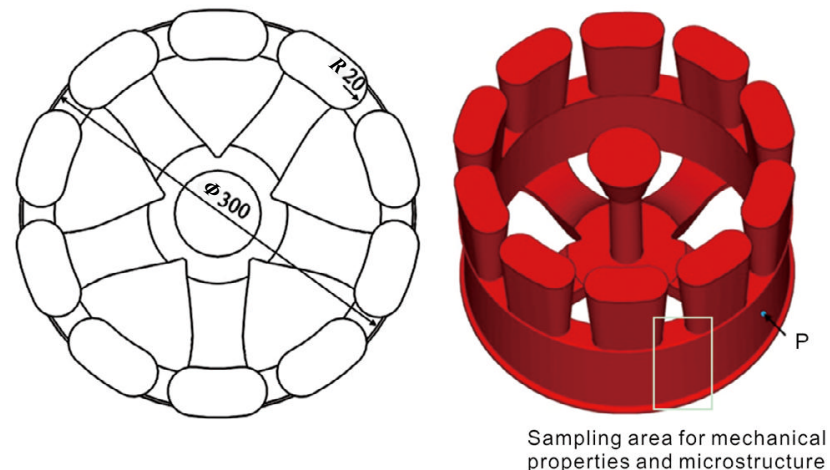

Fig. 7: Geometry of a round wall casting with a series of risers

\subsection{Skeletal sand mold design for casting}

Firstly, the casting was meshed into structured meshes, as shown in Fig. 8(a). Then, numerical simulation of the heat transfer between the casting and environment was performed. The obtained temperature field is shown in Fig. 8(b), which served as the base for the determination of the adaptive shell thickness of the sand mold. The obtained skeletal sand mold for the casting generated according to the above mentioned algorithm is shown in Fig. 9. The shell mold thickness varied from $15 \mathrm{~mm}$ to $25 \mathrm{~mm}$ with the local thickness of the casting, the truss section was $25 \mathrm{~mm}$ by $25 \mathrm{~mm}$, and the truss spacings in the $x, y$, and $z$ directions were $75 \mathrm{~mm}, 75 \mathrm{~mm}$, and $50 \mathrm{~mm}$, respectively. For the skeletal sand mold with reinforcing ribs, the shell mold thickness range was also set to $15 \mathrm{~mm}$ to $25 \mathrm{~mm}$, the cross section of ribs was $5 \mathrm{~mm}$, and their spacings in the $x, y$, and $z$ directions were $20 \mathrm{~mm}, 20 \mathrm{~mm}$, and $20 \mathrm{~mm}$, respectively.

\subsection{Printing of skeletal sand molds}

Silica sand is used as the molding sand for 3D printing, and its composition is shown in Table 1. The sand particle size ranged from $0.14 \mathrm{~mm}$ to $0.25 \mathrm{~mm}$. 
(a)

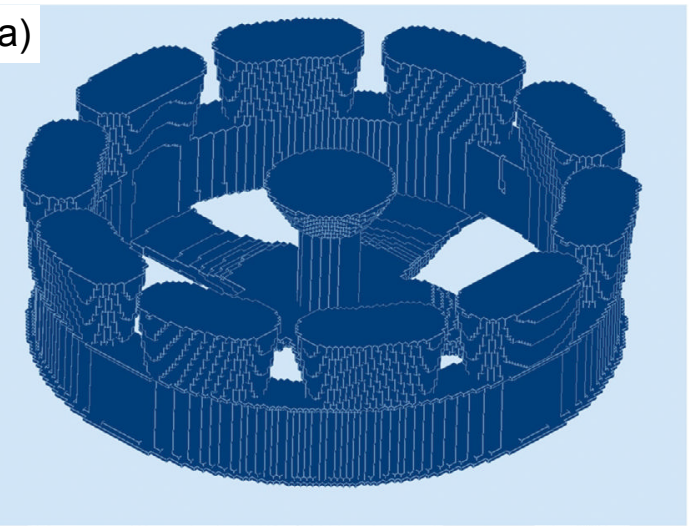

(b)

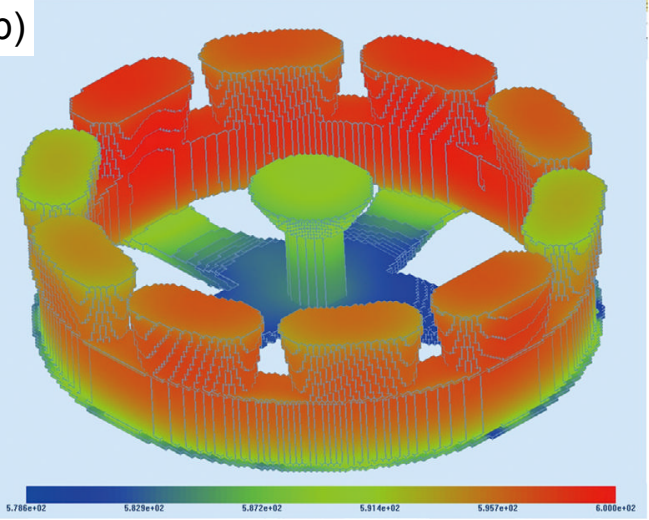

Fig. 8: Enmeshment of casting (a) and its temperature distribution which exhibit its thickness characteristics (b)

(a)

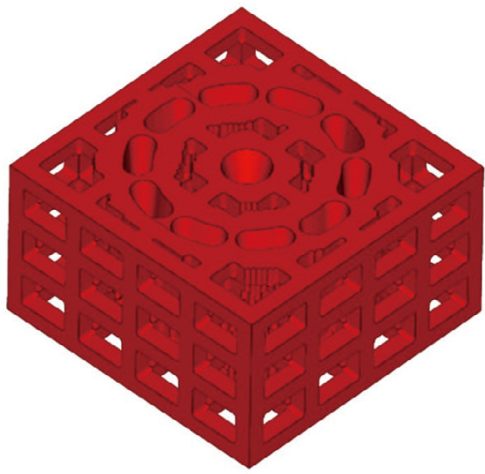

(b)

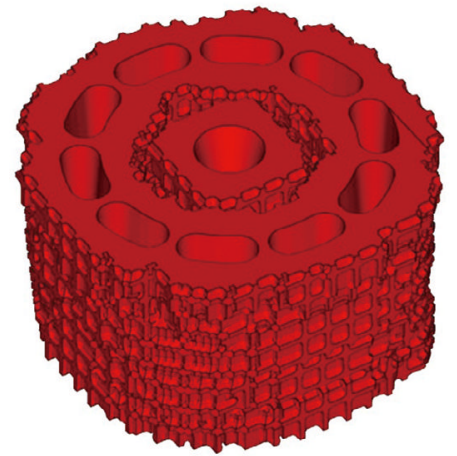

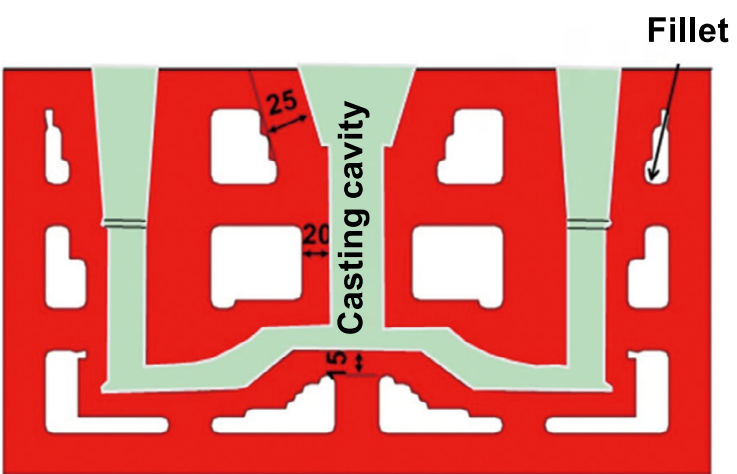

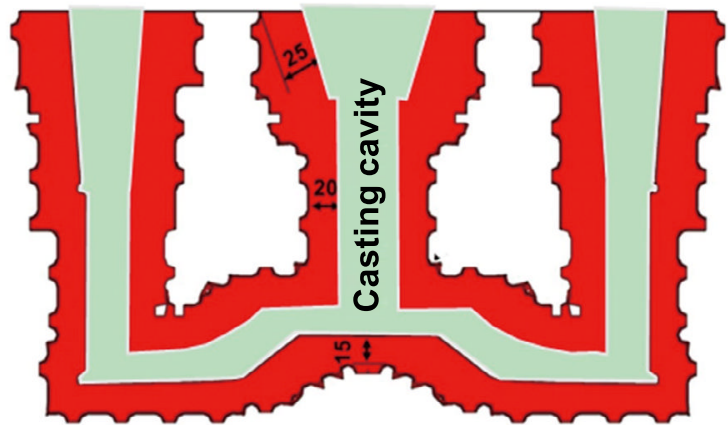

Fig. 9: Designed skeletal sand mold for round wall test casting: (a) lattice support structure; (b) rib enforced structure

Table 1: Composition of sand used for 3D printing

\begin{tabular}{cccccc} 
Composition & $\mathrm{SiO}_{2}$ & $\mathrm{Al}_{2} \mathrm{O}_{3}$ & $\mathrm{TiO}_{2}$ & $\mathrm{Fe}_{2} \mathrm{O}_{3}$ & Else \\
\hline Content (\%) & 99.50 & 0.22 & 0.21 & 0.03 & 0.04
\end{tabular}

The STL files of the designed hollow sand molds with lattice support and rib reinforcing structures served as the input to an ExOne-Smax machine. They were sliced, with each slice being responsible for a layer of sand and binder. During the printing process, binder was just sprayed on the designated areas of sand layers. The binder was furan resin, the total content was $1.6 \%$ to $1.8 \%$ of the weight of mold, and that of curing agent was $0.2 \%$. The layer thickness during printing was set as $0.25 \mathrm{~mm}$. The printed hollow molds are shown in Fig. 10.
The skeletal sand molds were treated as an integral structure without parting surfaces. Holes were drilled through the sand mold wall for the cleaning of the enclosed loose sand in the cavity, and then the cavity was checked by an industrial endoscope. Finally, these holes were plugged by high temperature resistance sealing paste, and left for hours to dry before pouring.

The designed shell-lattice and traditional molds are listed in Table 2. These new molds saved at least $54 \%$ of sand and resin, especially, $68 \%$ by the rib enforced structure, which is good for the reduction of printing cost and printing time, as well as environment protection. The cost is the main disadvantageous factor for the printing of sand molds, thus, the new design will bring a great impact on the application of additive making of sand molds. 
(a)

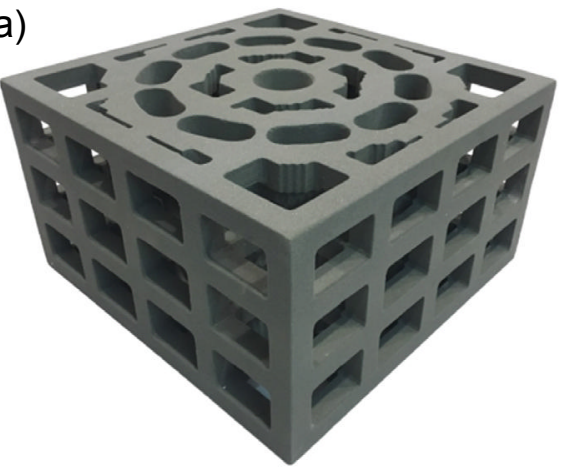

(b)

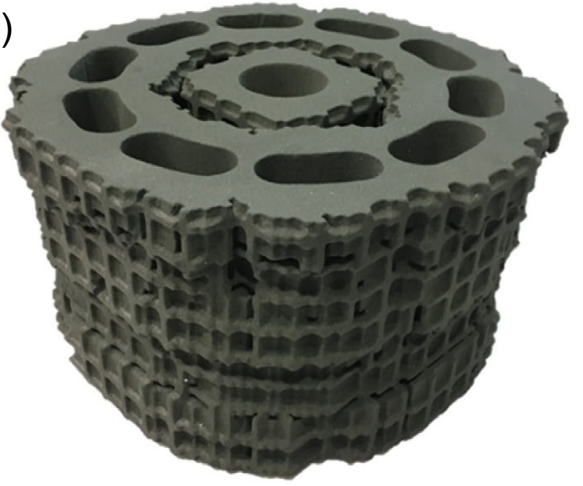

Fig. 10: Skeletal sand molds for the round wall casting printed by 3DP: (a) lattice support structure; (b) rib enforced structure

Table 2: Comparison of skeletal and traditional molds

\begin{tabular}{|c|c|c|c|c|c|}
\hline Type & $\begin{array}{l}\text { Shell thickness } \\
\qquad(\mathrm{mm})\end{array}$ & $\begin{array}{l}\text { Size of Lattice } \\
(\mathrm{mm})\end{array}$ & $\begin{array}{l}\text { Lattice or rib spacing } \\
\qquad(\mathrm{mm})\end{array}$ & $\begin{array}{l}\text { Weight } \\
\text { (kg) }\end{array}$ & $\begin{array}{c}\text { Weight reduction } \\
\text { rate (\%) }\end{array}$ \\
\hline $\begin{array}{l}\text { Dense sand mold } \\
\text { (traditional) }\end{array}$ & - & $\begin{array}{l}\text { Outbound box } \\
425 \times 425 \times 245\end{array}$ & - & 70.8 & - \\
\hline $\begin{array}{l}\text { Shell-lattice sand } \\
\text { mold }\end{array}$ & 10 & $25 \times 25$ & $75 \times 75 \times 50$ & 32.5 & 54 \\
\hline $\begin{array}{l}\text { Rib enforcing sand } \\
\text { mold }\end{array}$ & 10 & $5 \times 5$ & $20 \times 20 \times 20$ & 22.2 & 68 \\
\hline
\end{tabular}

\subsection{Casting experiment}

A356 aluminum alloy was melted in a crucible in a resistance furnace and held at $730{ }^{\circ} \mathrm{C}$. Then the melt was treated for 5 min by pressing refining and degassing agents (mainly chlorine salt) into it. The melt at $700{ }^{\circ} \mathrm{C}$ was poured into the skeletal sand molds at room temperature. Temperatures at the rim of the castings (Point $\mathrm{P}$ as shown in Fig. 7) and molds were measured by K-type thermocouples and the temperature distribution of the whole sand molds was measured using an infrared imaging camera (FLIR T460 made by FLIR Systems, Inc., USA).

These two round wall castings were cooled differently: natural convection for the skeletal sand mold with lattice support and water spray cooling for that with rib enforcement, as shown in Fig. 11. As the temperature of the melt at Point $\mathrm{P}$ fell below the solidus line, the pressurized water tank started to spray water mist on the hollow sand mold surface with rib reinforcing structure. Two water spray nozzles were used, one for the left side, the other for the right side. The two nozzles moved horizontally and then vertically to cover the whole casting, and then repeated. The water spray dispersion angle was $80^{\circ}$, the water drop was around 1-4 $\mathrm{mm}$ in diameter, and its flow speed was around $1.0 \mathrm{~m} \cdot \mathrm{s}^{-1}$. The spray nozzles turned around the sand mold every $3 \mathrm{~min}$. As the tiny water drops splashed on the hot mold surface, they turned into vapor immediately. There was no water drip from the mold surface. The mold seemed wet at the end of the casting process and still kept good strength, no collapse occurred. The round wall casting was shaken out as it reached $200{ }^{\circ} \mathrm{C}$.
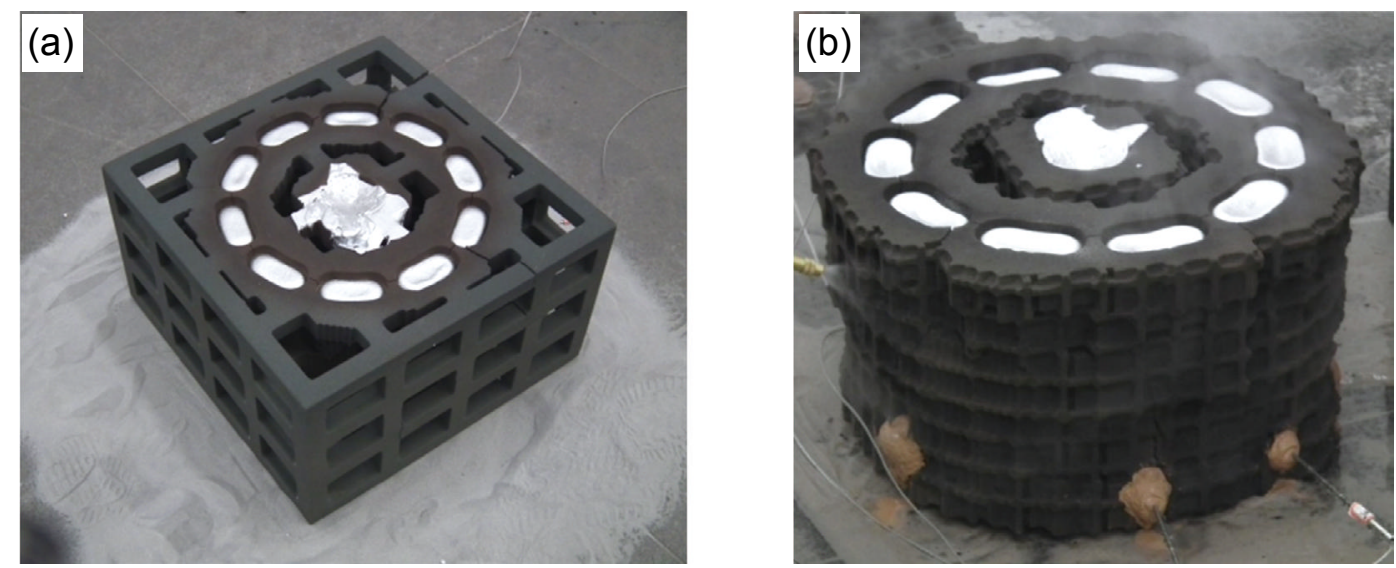

Fig. 11: Cooling of the round wall castings in two skeletal sand molds by different cooling methods: (a) natural convection; (b) forced cooling 
The obtained round wall castings by skeletal sand molds under two cooling conditions are shown in Fig. 12. Both castings are sound and smooth, the one formed in the rib enforced sand mold shows one flash. The surface roughness of the casting was

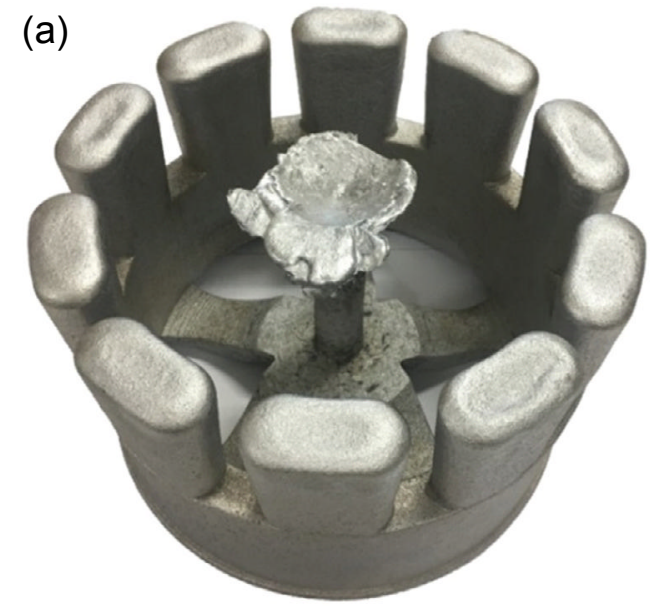

scanned by a three-dimensional scanner (FORM TALYSURF PGI800 made by Taylor Hobson Inc., UK). The surface finish reaches level four.

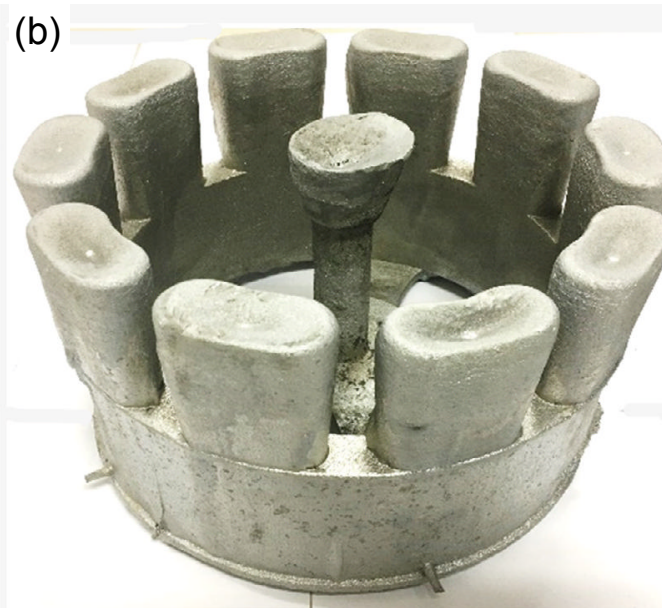

Fig. 12: Obtained round wall castings by natural cooling (a) and water spray cooling (b)

These two castings were scanned by a 3D scanner (HSCAN-300 made by Hangzhou Scantech Co., Ltd., China) and then 3D models were constructed. In comparing the scanned and designed models of the casting by software Geomagic Control, their deformation diagrams were acquired. RS200, a residual stress measurement device based on the blind hole method, a product of Vishay Precision Group, USA, was used to measure the surface residual stress of Point $\mathrm{P}$ on the rim of the hub castings, as shown in Fig. 13. Samples were taken on the hub rim of the castings for microstructural observation and mechanical properties testing. The sampling position is shown in Fig. 7. Tensile bars and microstructure samples were prepared from the cut samples. The microstructure was analyzed by a LEO-1450 scanning electron microscope. The tensile tests were conducted on a WDW-10E universal testing machine. The hardness tests were done by a TH604 Brinell hardness instrument with a cemented carbide indenter. The samples for hardness test measured $20 \mathrm{~mm} \times 20 \mathrm{~mm} \times 20 \mathrm{~mm}$.

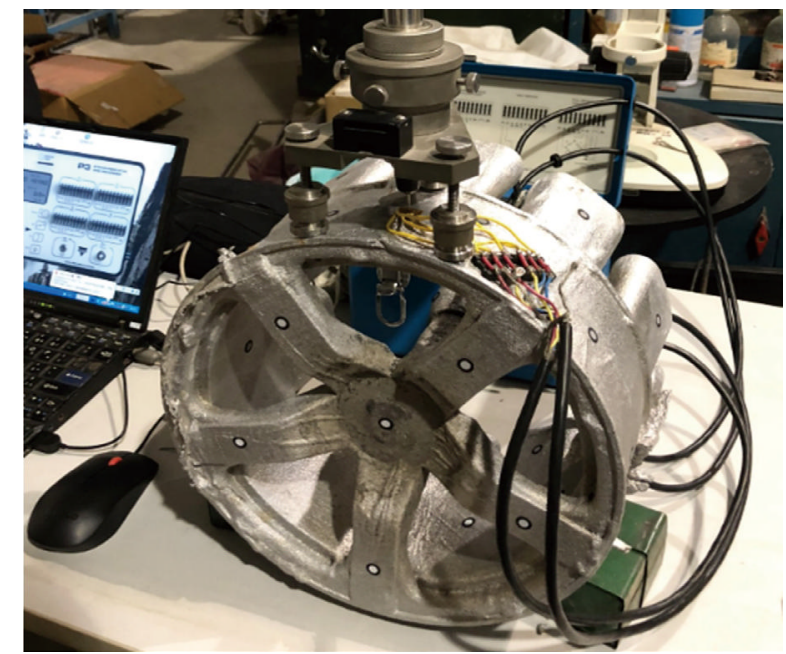

Fig. 13: Residual stress measurement of the wheel hub

\subsection{Results analysis}

During the casting process, the effects of natural cooling and water cooling on the cooling time, stress and deformation, microstructure and performance were investigated, and the experimental results were compared and analyzed.

\subsubsection{Comparison of natural cooling and forced cooling efficiency}

The surface temperature distribution pictures of the skeletal sand molds, taken by the infrared thermal imaging camera, are shown in Fig. 14. When the skeletal sand mold with lattice support structure was naturally cooled for $1,000 \mathrm{~s}$, the sand mold surface reached $360{ }^{\circ} \mathrm{C}$ at the area corresponding to risers, however, the furthest lattice corner was just about $60^{\circ} \mathrm{C}$. After 5,000 s, the peak temperature of the sand mold surface fell to about $180{ }^{\circ} \mathrm{C}$, while the lowest temperature was lower than $60^{\circ} \mathrm{C}$.

For the skeletal sand mold with reinforcing ribs, firstly, it was naturally cooled for $800 \mathrm{~s}$, its highest surface temperature reached about $340{ }^{\circ} \mathrm{C}$, and the measured temperature of the rim indicated that the casting had completely solidified. Secondly, the water cooling started. After a total of $2,700 \mathrm{~s}$, the peak temperature of the sand mold surface decreased to about $180^{\circ} \mathrm{C}$.

The temperature variations with time of the rim of the round wall castings and the corresponding position of the shell surface of these two skeletal sand molds were extracted from the infrared photos, and are shown in Fig. 15. The cooling curves of the casting and mold under two cooling conditions showed significant difference. The casting with the skeletal sand mold began to solidify after $500 \mathrm{~s}$ and completely solidified after $800 \mathrm{~s}$. For natural cooling, it took the round wall casting 7,000 s to drop to the shakeout temperature of $200{ }^{\circ} \mathrm{C}$. It took the shell surface of skeletal sand mold $1,000 \mathrm{~s}$ to reach the peak temperature of $350{ }^{\circ} \mathrm{C}$. The temperature range of the shell mold corresponding to the wheel rim was $350-180{ }^{\circ} \mathrm{C}$ during the natural cooling 
(a)

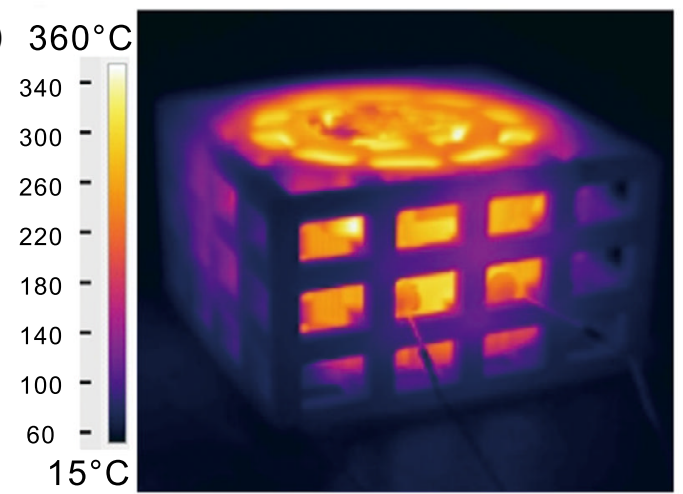

(c)

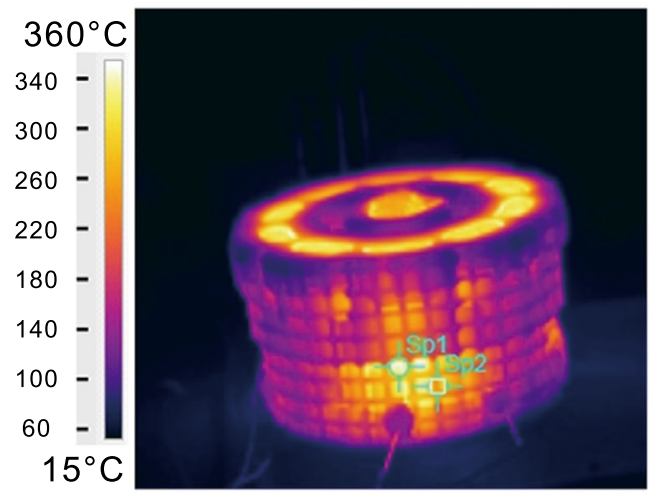

(b)

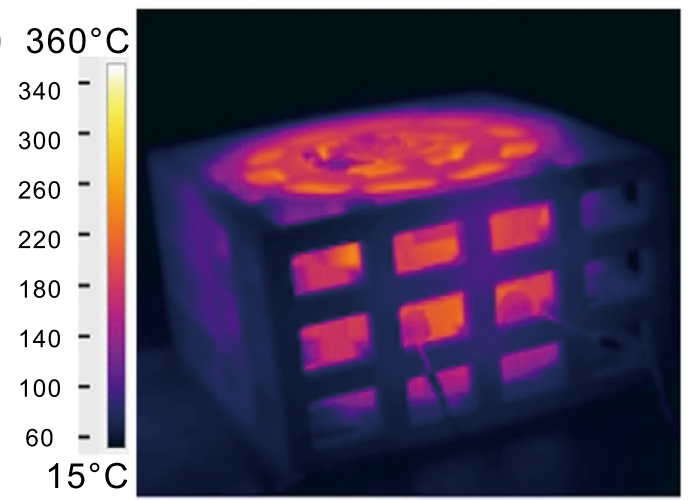

(d)

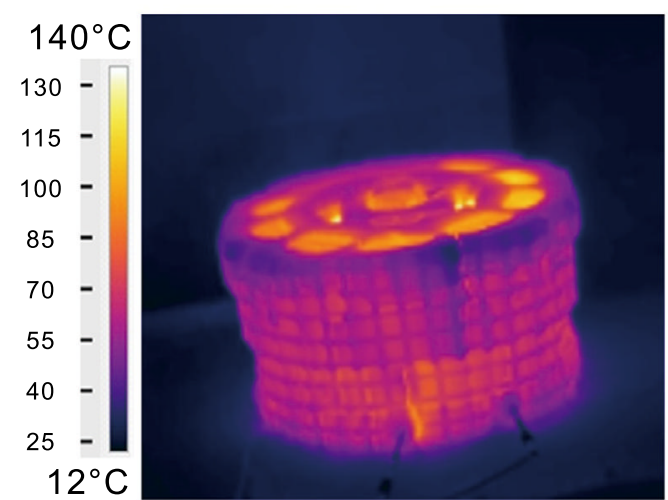

Fig. 14: Infrared imaging of the sand mold during the casting process of the casting: (a) skeletal sand mold with lattice by natural cooling at $1,000 \mathrm{~s}$; (b) skeletal sand mold with lattice by natural cooling at $5,000 \mathrm{~s}$; (c) rib enforced sand mold by water spray cooling at $800 \mathrm{~s}$; (d) rib enforced sand mold by water spray cooling at 2,700 s

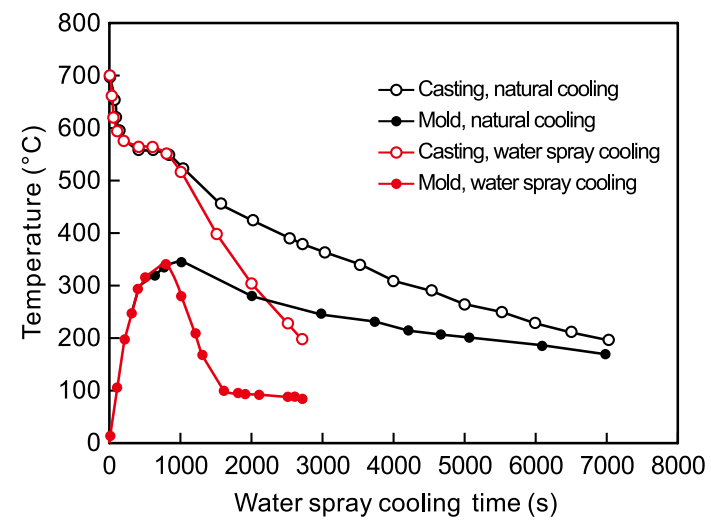

Fig. 15: Cooling curves of the round wall castings and skeletal sand molds

stage. As the cooling proceeded, the temperature difference between the casting and mold gradually decreased to $28{ }^{\circ} \mathrm{C}$. For water spray cooling conditions, it took the casting only 2,700 $\mathrm{s}$ to drop to the shakeout temperature. The shell surface of the skeletal sand mold reached the peak temperature of $350{ }^{\circ} \mathrm{C}$. Then the shell surface temperature fell sharply as water spray cooling was adopted, and finally reached a level of about $80^{\circ} \mathrm{C}$. The shell mold temperature varied from $350^{\circ} \mathrm{C}$ to $80^{\circ} \mathrm{C}$ during the water cooling process. The temperature difference between the sand mold and the casting decreased first and then kept at a relative stable value, which means a stable cooling rate was reached during the water spray cooling. The cooling time of the casting under water cooling was reduced by $4,300 \mathrm{~s}$, the cooling efficiency was increased by $62 \%$, which greatly shortened the time to shakeout.

This phenomenon was due to the fact that the skeletal sand mold is sensitive to water cooling. The mold surface temperature under water spray cooling is significantly lower than that under natural cooling, which means the heat release from the casting is greatly absorbed by the sprayed water. Meanwhile the lower surface temperature of the sand mold increases the temperature discrepancy between the sand mold and casting, and the great temperature gradient leads to good heat transfer. Therefore, the casting under water cooling shows a faster cooling rate, a greater slope of the cooling curve, and a shorter time to shakeout during the casting process.

\subsubsection{Effect on residual stress}

The circumferential residual stress of the hub casting under natural cooling was $55 \mathrm{MPa}$, in tensile state; while, that of the casting under water cooling was $-31 \mathrm{MPa}$, in compressive state. This shows that the action of water cooling alters the stress state of the casting rim surface. The temperature difference between the internal and external surfaces of the rim determines its residual stress. The greater the temperature difference, the lower the tensile stress or even compressive stress. The water spray cooling greatly facilitates the cooling of the external surface of the rim, but a little effect on the internal surface. This leads to a greater temperature difference between the internal and external surfaces. As the internal surface of the rim contracts finally, the external surface is compressed, which results into compressive 
stress. Compared with tensile stress state, the surface compressive stress is beneficial to the performance of the casting.

Deformation diagrams of these two round wall castings by natural cooling and water cooling were acquired, and the sections of the rim were compared, as shown in Fig. 16. Both the internal and external rings of the rim under natural cooling and water spray cooling conditions exhibit a central contraction of $1.0 \mathrm{~mm}, 1.5 \mathrm{~mm}, 1.0 \mathrm{~mm}$, $1.4 \mathrm{~mm}$, respectively. The rim under water spray cooling leads to less
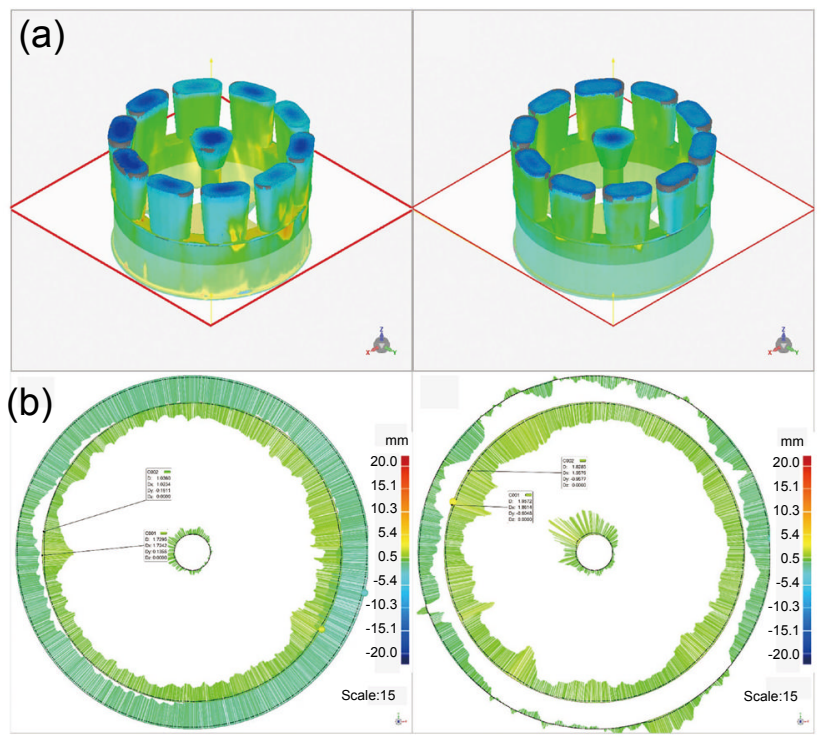

Fig. 16: Comparison of deformation of the wheel rim:

(a) location of sections deformation of wheel rim;

(b) displacement in radial direction is magnified 15 times contraction of the external surface of the rim compared to that with natural cooling. That is because of the enough time for contraction in the latter condition. The contraction of the rim under natural cooling is more uniform, that of the rim under water spray cooling is not uniform. The reason is that moving water spray nozzles leads to fluctuating cooling. If a number of nozzles are arranged surrounding the sand mold, the contraction of the rim will be uniform. The skeletal sand mold design provides the cooling control possibility, if the cooling is exerted in different periods, the deformation can be reduced. For example, as the casting reaches high strength, forced cooling can improve the cooling efficiency with less deformation.

\subsubsection{Effect on microstructure}

The as-cast microstructures of the round wall casting under natural cooling and water cooling are shown in Fig. 17. The microstructure of the hub casting is mainly consisted of primary $\alpha$-Al and eutectic structure of $\alpha$-Al and $\mathrm{Si}$ phases. The morphology of eutectic $\mathrm{Si}$ is palletlike. The eutectic Si aggregately disperses among the $\alpha$-Al grains. Cracks and shrinkage cavities occur in the aggregation region of the eutectic Si phase. The secondary dendrite arms of the $\alpha-\mathrm{Al}$ substrate are relatively smooth. The microstructure of the round wall castings under water spray cooling differs from that under natural cooling with more round dendrite arms of $\alpha-\mathrm{Al}$ and finer eutectic silicon phase of rod or granular shapes.
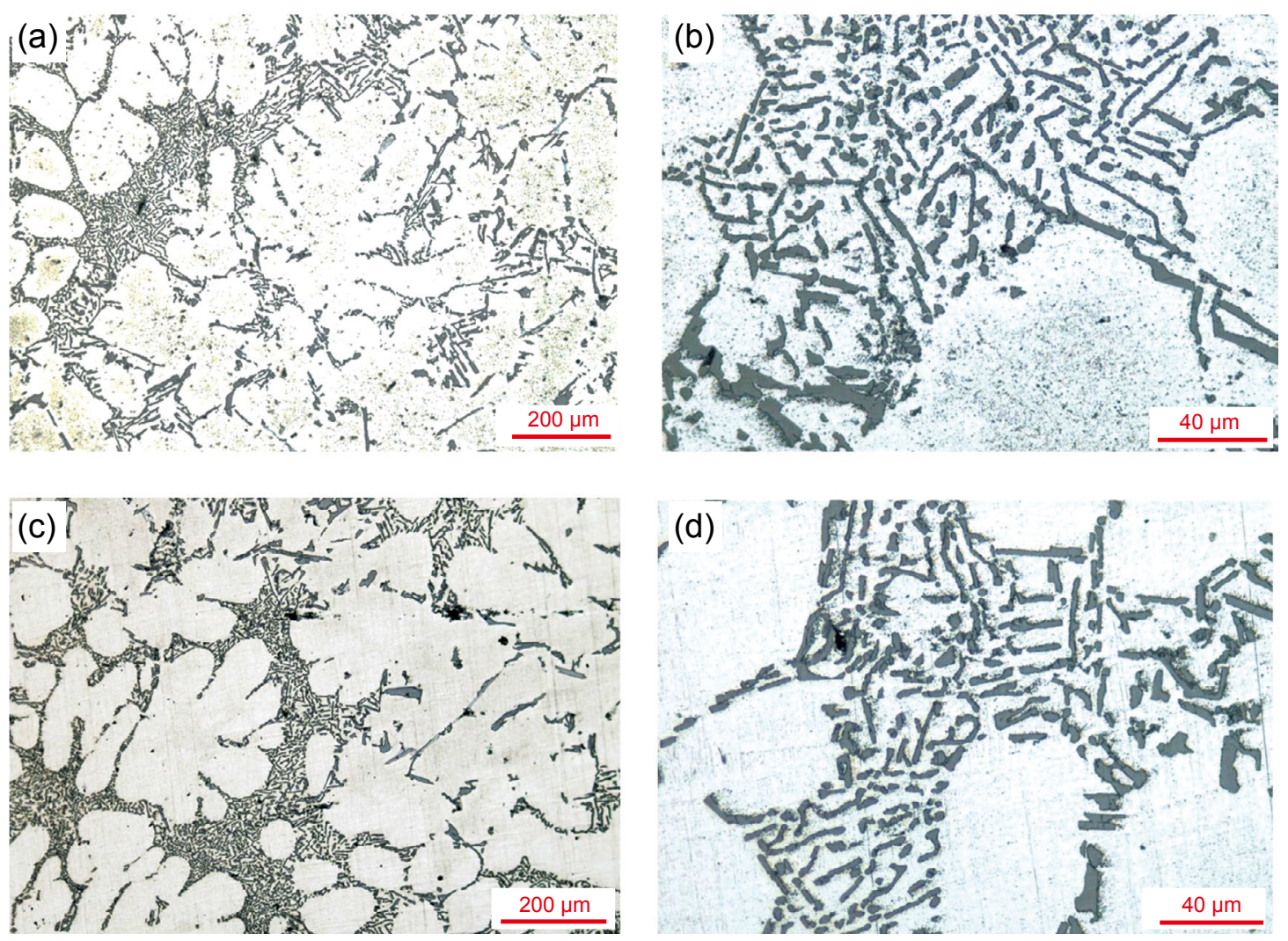

Fig. 17: Microstructures of wheel hub: ( $a$ and b) natural cooling; (c and d) water spray cooling 
Figure 18 shows the SEM images and EDS results of the castings under natural cooling and water cooling conditions. The $\mathrm{Mg}$ and $\mathrm{Cu}$ contents in the $\mathrm{Al}$ substrate are $0.69 \mathrm{wt} . \%$, $0.07 \mathrm{wt} . \%$ under natural cooling, respectively, but they are improved to $0.80 \mathrm{wt} . \%, 0.11 \mathrm{wt} . \%$ under water cooling, respectively. The water cooling makes the casting cool faster, hinders the precipitation of $\mathrm{Cu}$ and $\mathrm{Mg}$ from the $\mathrm{Al}$ substrate, so the concentration of $\mathrm{Cu}$ and $\mathrm{Mg}$ in the matrix is higher. Therefore, the castings under water cooling possess higher strength and hardness than the casting under natural cooling.
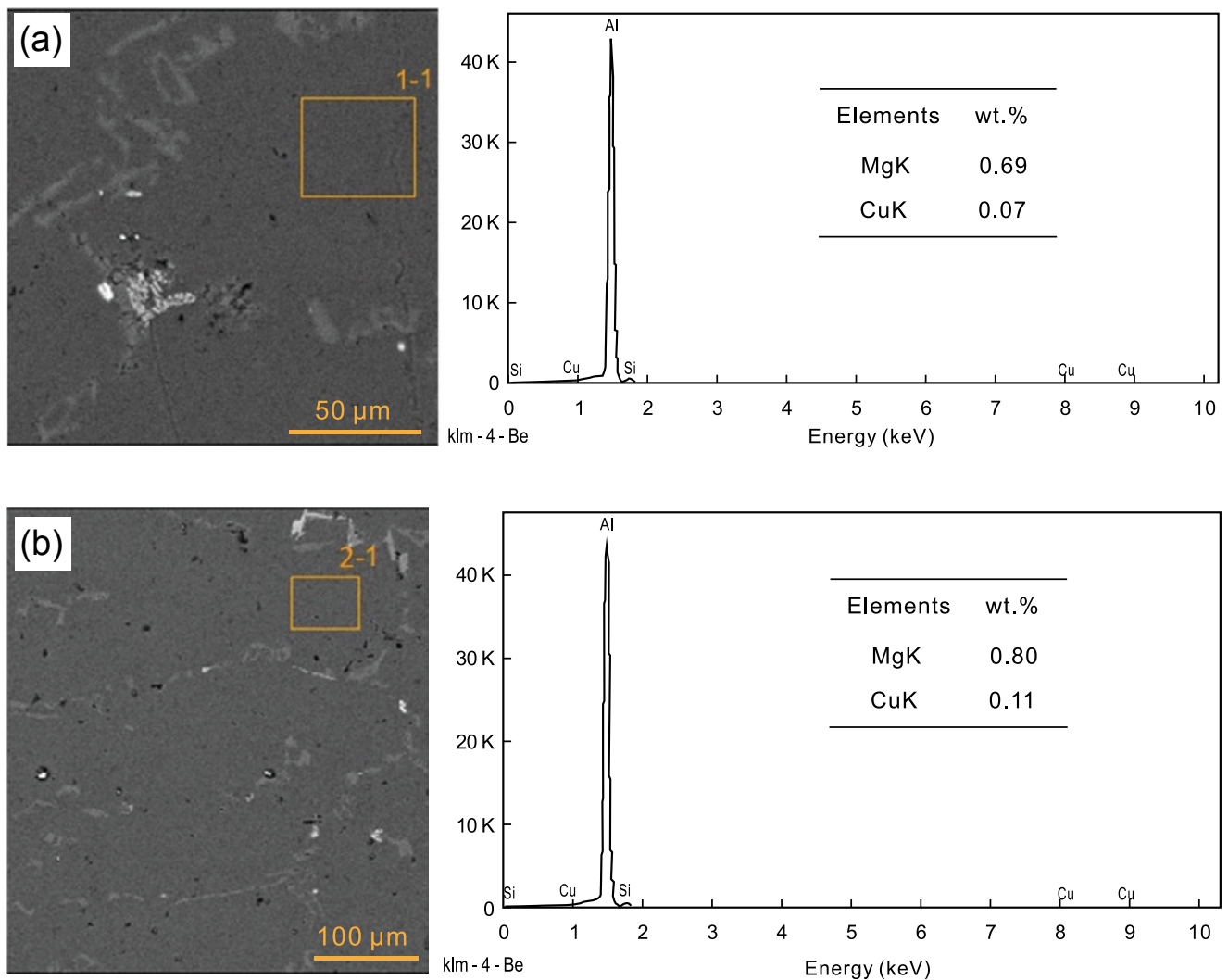

Fig. 18: EDS results of $\mathrm{Mg}$ and $\mathrm{Cu}$ contents in matrix within the scanned Area 1-1: natural cooling (a), and Area 2-1: water spray cooling (b)

\subsubsection{Effect on mechanical properties}

Mechanical properties are shown in Table 3. The tensile and yield strengths of the casting under water cooling are slightly higher than that under natural cooling condition. This is because the forced cooling causes surface compressive stress, meanwhile, the higher content of $\mathrm{Cu}$ and $\mathrm{Mg}$ in the matrix leads to solution strengthening. The hardness value of the hub casting under natural cooling was $51.3 \mathrm{HB}$, and that of the casting under water cooling was $57.6 \mathrm{HB}$. Thus, water cooling is beneficial to the improvement of hardness. The mechanical properties are greatly determined by the internal quality of the castings. Under the same melting condition, the strength of the casting under water spray cooling is higher than that under natural cooling.

\subsubsection{Cracks of hollow sand molds}

Cracks appears on the hollow sand mold surface after the solidification of the round wall casting. The main position is the joint between the struts and the sharp transition of the shell mold. The reason is the contraction of the castings during the casting process. However, the cracks do not affect the quality of the castings.

Table 3: Comparison of as-cast mechanical properties of castings under natural and water spray cooling

$\begin{array}{ccccc}\text { Cooling condition } & \begin{array}{c}\text { Hardness } \\ (\mathrm{HB})\end{array} & \begin{array}{c}\text { Tensile strength } \\ \boldsymbol{R}_{\mathrm{m}}(\mathrm{MPa})\end{array} & \begin{array}{c}\text { Yield strength } \\ \boldsymbol{R}_{\mathrm{p} 0.2}(\mathrm{MPa})\end{array} & \begin{array}{c}\text { Elongation } \\ \mathbf{A}(\%)\end{array} \\ \text { Natural cooling } & 51.3 & 118 & 83 & 1.5 \\ \text { Water spray cooling } & 57.6 & 126 & 88 & 1.5 \\ \text { Traditional sand mold }{ }^{[26]} & - & 132 \pm 9.5 & 68 \pm 3.5 & 2.5 \pm 1.1\end{array}$




\section{Conclusions}

A comprehensive closed-loop cooling control of castings by adopting a skeletal sand mold design was proposed and was applied to a round wall test casting. Two kinds of skeletal sand molds, one with lattice support and the other with rib enforced sand molds were designed and printed out by $3 \mathrm{D}$ printing method. Aluminum round wall castings were produced by using these two sand molds, one was under natural cooling, the other under water spray cooling. The sand mold surface temperature, cooling curves, microstructures, and mechanical properties of the castings were compared and discussed.

(1) By using both skeletal sand molds and different cooling conditions, sound castings were obtained with good surface finish of level four although no paint was coated on the internal surface of the sand mold, and no spur was found because of the unit design of the sand mold.

(2) The skeletal sand molds are at least 54\% lighter than the traditional dense sand mold.

(3) Water spray cooling increases the cooling speed of the casting by $62 \%$, saving $4,300 \mathrm{~s}$.

(4) The surface residual stress of the round wall casting under water spray cooling is in compressive state instead of the tensile state under natural cooling, i.e., forced cooling can be used to adjust the surface stress state of a casting.

(5) The microstructure of the round wall casting under water spray cooling differs from that under natural cooling, with more round dendrite arms of $\alpha-\mathrm{Al}$ and more finer eutectic silicon phase of rod or granular shapes.

(6) The hardness and mechanical properties are increased by using water spray cooling because higher $\mathrm{Cu}$ and $\mathrm{Mg}$ contents are kept in the aluminum matrix.

\section{Acknowledgement}

This project was funded by the National Natural Science Foundation of China (No. 51875308).

\section{References}

[1] Karkkainen M, Nastac L. Numerical modeling of convective heat transfer for turbulent flow in "bubbler" cooling channels. JOM, 2019, 71: 772-778.

[2] Norwood A J, Dickens P M, Soar R C, et al. Analysis of cooling channels performance. International Journal of Computer Integrated Manufacturing, 2004, 17: 669-678.

[3] Showman R E, Aufderheide R C, Yeomans N P. Advances in thin-wall sand casting. In: Proc. 67th World Foundry Congress, The Institute of Cast Metals Engineers, 2006: 430-439.

[4] Au K M, Yu K M. Conformal cooling channel design and CAE simulation for rapid blow mould. The International Journal of Advanced Manufacturing Technology, 2012, 66: 311-324.

[5] Grassi J, Campbell J, Hartlieb M, et al. The ablation casting process. Materials Science Forum, 2009, 618: 591-594.

[6] Upadhyay M, Sivarupan T, Mansori M E. 3D printing for rapid sand casting - A review. Journal of Manufacturing Processes, 2017, 29: 211-220
[7] Kang Jin-wu, Ma Qiang-xian. The role and impact of 3D printing technologies in casting. China Foundry, 2017, 14(3): 157-168.

[8] Tomita Y, Fukuda Y. Application of sand mold creation by 3D printer with artificial sand. In: Proc. 71st World Foundry Congress, Spain, 2014.

[9] Wang $X \mathrm{H}$, Fuh J Y H, Wong $Y$ S, et al. Laser sintering of silica sand-mechanism and application to sand casting mould. International Journal of Advanced Manufacturing Technology, 2003, 21: 1015-1020.

[10] Casalino G, Filippis L A C De, Ludovico A. A technical note on the mechanical and physical characterization of selective laser sintered sand for rapid casting. Journal of Materials Processing Technology, 2005, 166: 1-8.

[11] Crommert S, Seitz S, Esser K K. Die and investment cast parts via the sls $\AA$ selective laser sintering process. In: Proceedings of SPIE, 1997, 3012: 95-105.

[12] Utela B, Storti D, Anderson R, et al. A review of process development steps for new material systems in three dimensional printing (3DP). Journal of Manufacturing Processes, 2008, 10: 96-104.

[13] Hackney P, Wooldridge R. Optimisation of additive manufactured sand printed mould material for aluminium castings. Procedia Manufacturing, 2017, 11: 457-465.

[14] Woods K and Ravi S. Desgin considerations for 3-D-printed cores and molds. Modern Casting, 2015, 105(5): 24-29.

[15] Wu H, Li D, Tang Y. Fabrication of integral core/shell ceramic casting mould for hollow turbine blade. Applied Mechanics and Materials, 2013, 248: 231-236.

[16] Sama S R, Wang J, Manogharan G. Non-conventional mold design for metal casting using 3D sand-printing. Journal of Manufacturing Processes, 2018, 34: 765-775.

[17] Dutta B, Froes F H. The additive manufacturing (AM) of titanium alloys. Titanium Powder Metallurgy, Science, Technology and Applications, 2017, 72: 96-106.

[18] Fryazinov O, Vilbrandt T, Pasko A. Multi-scale space-variant FRep cellular structures. Computer-Aided Design, 2013, 45(1): 26-34.

[19] Wang X. Simulation driving design - for 3D printing. Metal Processing, 2016, 2: 39-40.

[20] Shangguan H L, Kang J W, Yi J L, et al. The design of the 3D printed lattice reinforced thickness-varying shell mold for casting. Materials, 2018, 11: 535.

[21] Deng C Y, Kang J W, Shangguan H L, et al. Effects of hollow structures in sand mold manufactured using 3D printing technology. Journal of Materials Processing Technology, 2018, 255: 516-523.

[22] Shangguan H L, Kang J W, Deng C Y. 3D-printed shelltruss sand mold for aluminum castings. Journal of Materials Processing Technology, 2017, 250: 247-253.

[23] Shangguan H L, Kang J W, Deng C Y, et al. 3D-printed rib-enforced shell sand mold for aluminum castings. The International Journal of Advanced Manufacturing Technology, 2018, 96: 2175-2182.

[24] Wang J W, Zheng L L, Kang J W, et al. Study on the directional solidification process of an aluminum alloy bar in multi-shell mold being gradually immersed in water. Materials, 2020, 13: 2197.

[25] Chen Y. A Mesh-based Geometric Modeling Method for General Structures. In: Proc. ASME International Design Engineering Technical Conferences and Computers and Information in Engineering Conferences, 2006: 269-281.

[26] Boastani A F, Tahamtan S. Microstructure and mechanical properties of A356 thixoformed alloys in comparison with gravity cast ones using new criterion. Transactions of Nonferrous Metals Society of China, 2010, 20(9): 1608-1614. 